\title{
Galvin Task Force Recommendations Given on the Future of DOE National Laboratories
}

The Department of Energy (DOE) is an important organization for the members of the Materials Research Society. Over $20 \%$ of MRS members work at Department of Energy laboratories. Many more of our university and industrial members carry out research and development activities at large DOE facilities-such as synchrotron and neutron scattering facilities-and at the many user facilities operated by the laboratories. In addition, the Basic Energy Sciences Division supports extensive materials-related research and development activities in universities.

Last year, DOE Secretary Hazel O'Leary appointed a Task Force on Alternative Futures for the Department of Energy National Laboratories, chaired by Robert Galvin, former CEO of Motorola. After ten months of study, the Task Force issued its preliminary report February 1, 1995.

The report supports existing missionrelated activities at the laboratories, but suggests that the laboratories pull back expansion of their activities into new mission areas, "[We] see the laboratories as having clear areas of expertise, yet limited to their traditional mission areas of national security, energy, and environmental science and technology, as well as in the fields of fundamental science which underpin these mission areas and in basic science associated with high energy, nuclear, and condensed matter physics...." In addition to the need to focus within its mission areas, it urges the laboratories to renew and press the frontiers in its energy agenda as "a priority concern as an ongoing national strategic issue."

Stressing the importance for long-range basic research underlying the laboratories' traditional missions, the report states that "the laboratories' research role is part of an essential, fundamental cornerstone for continuing leadership by the United States." The Task Force argues that the laboratories should sharpen their strategic focus on areas of established excellence and borrow a page from the private sector where companies achieve major performance improvements by consolidating their essential strengths. It urges that the laboratories strengthen their efforts in fundamental science and engineering and better integrate their fundamental science programs with their mis- sion-driven research and with the rest of the national $R \& D$ enterprise. The report further states that energy and environmental R\&D at the laboratories must be more closely integrated.

If these recommendations are pursued, the recent emphasis on industry-national laboratory-university partnerships could receive additional attention. These views are consistent with MRS's tradition of emphasizing a multidisciplinary approach and integrating both the fundamental and applied aspects of an area.

The Task Force gives special attention to the national security mission performed by Los Alamos National Laboratory, Lawrence Livermore National Laboratory, and Sandia National Laboratories. The report supports DOE's science-based stockpile stewardship program to ensure the safety, security, and reliability of the stockpile in the absence of nuclear testing. The report advises against transferring DOE weapons laboratories to the Department of Defense. It finds excess capacity for nuclear design and recommends that Lawrence Livermore Laboratory retain the technical base to continue nonproliferation, counter-proliferation, verification, and intelligence support, but that activities in nuclear materials design and production be transferred to Los Alamos over the next five years.

The Task Force concludes that industrial competitiveness is not an appropriate primary mission of the laboratories, but should be viewed as a derivative, or outcome, of the other core missions of the DOE, "The laboratories should not aspire to become research boutiques for industries." Through its partnerships with industry, the Department helps to maximize the value of the public investment in these institutions by increasing prospects of getting taxpayer-financed innovations to the marketplace while also meeting

A complete copy of the report, "Alternative Futures for the Department of Energy National Laboratories," issued by the Galvin Task Force on February 1, 1995, can be obtained over the Internet on the Department of Energy's homepage at http:/ / www. doe.gov.
DOE mission requirements. The Task Force concludes that the laboratories should concentrate on longer term R\&D closely aligned with DOE's missions.

The Task Force indicts congressional micromanagement and excessive oversight by DOE and other regulatory bodies and recommends a new and innovative governance structure for the laboratories. The report notes that the management system of the laboratories is costly, bureaucratic, and inefficient-due to a 40 year legacy of creeping micromanagement and uncoordinated and excessive oversight of the laboratories by Congress, DOE, and multiple review bodies. The report recommends that DOE oversight of the laboratories be based on performance instead of the current system of compliance-based directives.

The existing laboratory system is said to be oversized due to management inefficiencies and political considerations that have inhibited downsizing. No specific laboratory closures are recommended, but downsizing is urged through a process which disciplines each laboratory to concentrate on areas of excellence and divest from areas of mediocrity. Materials research is a mission-relevant area of excellence at the laboratories. Thus one would hope that this area would remain prominent even in the event of a downsizing.

How DOE decides to treat recommendations from the Task Force could have a major effect on a significant number of MRS members. Many of our members from universities and industry rely on the user facilities at the laboratories, and with the recent emphasis on technology transfer, interactions between the laboratories and industry have increased significantly. For example, DOE laboratories have entered into more than 1,000 Cooperative Research and Development Agreements (CRADAs) with industrial partners. As a result, actions taken could affect not only MRS members at the laboratories but also some of those in universities and industry.

PAUl S. PeErCY

Paul S. Peercy is a member of the MRS Public Affairs Committee and director of Microelectronics and Photonics at Sandia National Laboratories. 